\title{
ANALYSIS AND DESIGN OF CONTINUOUS-PROFILE CIRCULAR WAVEGUIDE MODE CONVERTERS USING THE COUPLED-INTEGRAL-EQUATIONS TECHNIQUE
}

\author{
Jens Bornemann* and Smain Amari \\ Department of Electrical and Computer Engineering \\ University of Victoria, Victoria, B.C., Canada V8W 3P6
}

\section{INTRODUCTION}

Mode converters in circular waveguide technology are widely used in high-power microwave and millimeter-wave applications, e.g. [1] - [9]. Of specific importance are those involving gyrotrons where periodic (e.g. Fig. 1) or aperiodic (e.g. Fig. 3) $\mathrm{TE}_{0 \mathrm{n}}$-to-TE $\mathrm{TE}_{01}$-mode converters are utilized [5] - [9].

Whereas the computer-aided analysis and design of general circular waveguide structures are well known, e.g. [10], severe restrictions, which make a straight-forward CAD procedure cumbersome and slow, apply for the design of high-power converters. In order to avoid breakdown effects, the following two constraints are imposed: First, the radius within the mode converter must be larger than that at the input or output. This contributes to an increased number of waveguide modes to be considered and, therefore, increases the size of the matrices to be processed. Secondly, the longitudinal profile of the converter must be continuous. The analysis of such structures is predominantly performed by staircasing with the number of steps increased until convergence is reached. Both conditions lead to high CPUtime and memory requirements as large numbers of both steps and modes need to be handled simultaneously.

More recently, the coupled-integral equations technique (CIET) has been introduced, e.g. [11], [12]. Two of the main advantages of this technique are, first, the creation of a block-diagonal matrix whose size depends only on the number of basis functions and, secondly, the possibility of including a large number of modes without increasing the size of or the number of entries in the block-diagonal matrix. As will be demonstrated here, these two features make the CIET very well suited to analyze and design continuous-profile circular waveguide mode converters for high-power applications.

\section{THEORY}

The general principles of extracting the generalized S-matrix from a CIET algorithm is outlined in [11], [12]. For the interested reader, a more detailed presentation is currently in press [13].

For the analysis of general circular waveguide components, the structure is divided into a number of steps, each of which is treated as a seperate discontinuity. The electromagnetic field at that discontinuity is related only to the fields of the immediate neighbour discontinuities which are expressed by a set of basis functions. Depending on the actual discontinuity, the basis functions are either chosen as the set of modes in the smaller of the two waveguides (region I of radius $r_{1}$ ) 


$$
\vec{\Phi}(\rho, \varphi)=\sum_{r}\left[\nabla \mathrm{T}_{\mathrm{hr}}^{\mathrm{I}}(\rho, \varphi) \times \overrightarrow{\mathrm{e}}_{\mathrm{z}}\right] \mathrm{c}_{\mathrm{r}}+\sum_{\mathrm{s}}\left[-\nabla \mathrm{T}_{\mathrm{es}}^{\mathrm{I}}(\rho, \varphi)\right] \mathrm{c}_{\mathrm{s}} .
$$

or can include the proper edge condition by dividing (1) by

$$
\left[1-\left(\rho / r_{1}\right)^{2}\right]^{1 / 3} \text {. }
$$

In (1), $r$ and $s$ denote the numbers of TE- and TM-mode basis functions with their respective coefficients $c_{r}$ and $c_{s}$. Note that (1) covers the general cases of TE-toTM- and TM-to-TM-mode converters. $\mathrm{TE}_{0 \mathrm{n}}$-mode structures are calculated with $\mathrm{s}=0$ and $\mathrm{r} \leftarrow[0, \mathrm{n}]$, thus representing the $\mathrm{TE}_{0 \mathrm{n}}$-mode approach.

The general algorithm of the CIET applied to a variety of waveguide discontinuities, including as well as excluding edge conditions, has been verified by comparison with other numerical methods and measurements in [11] - [13]. Therefore and for lack of space, a direct comparison is omitted here. The reader is referred to [11] - [13] for further details.

\section{RESULTS}

In order to verify this technique, the $\mathrm{TE}_{02}$-to- $\mathrm{TE}_{01}$-mode converter of [5] was analyzed and tested for convergence. It was found that eight modal basis functions, 150 modal expansion terms and 200 steps to approximate the continuous profile were sufficient. These results were confirmed within negligible deviations by an independently created code using up to 400 steps.

The dashed lines in Fig. 2 show the performance of the $\mathrm{TE}_{02}$-to-TE $\mathrm{T}_{01}$-mode converter of [5]. Over a five-percent and ten-percent bandwidth centered at $60 \mathrm{GHz}$, the $\mathrm{TE}_{02}$-mode return loss is better than 34 and $32 \mathrm{~dB}$, respectively.

In order to improve the return loss, a MiniMax-based optimization strategy [14] was employed with three additional constraints: First, the overall length of the converter was not to be altered; secondly, the radius ratio at individual step discontinuities was to remain below a given value to approximate a continuous profile; and thirdly, all radii were to exceed those of the input and output ports. Allthough the profile is changed only very slightly (c.f. Fig. 3) and the $\mathrm{TE}_{02}$-to-TE $\mathrm{T}_{01}$-mode insertion loss remains virtually identical, the $\mathrm{TE}_{02}$-mode input return loss is increased to better than $45 \mathrm{~dB}$ over the entire ten-percent bandwidth and to better than $60 \mathrm{~dB}$ over a five-percent bandwidth. The overall improvement of the optimized design is obvious in the solid line of Fig. 2 .

\section{CONCLUSIONS}

The coupled-integral-equations technique is an excellent tool for the analysis and optimization of continuous-profile circular waveguide mode converters. Its salient features keep the CPU-time requirements within limits and allow the user to arrive at a high-performance design within time frames typical for applications in an industrial environment. The method has been demonstrated at the example of a $60 \mathrm{GHz} \mathrm{TE}_{02}$-to- $\mathrm{TE}_{01}$-mode converter achieving more that $60 \mathrm{~dB}$ return loss over a five-percent bandwidth. 


\section{REFERENCES}

[1] E. Lunéville, J.-M. Krieg and E. Giguet, "An original approach to mode converter optimum design", IEEE Trans. Microwave Theory Tech., Vol. 46, pp. 1-9, Jan. 1998.

[2] M. Thumm, A. Jacobs, and M. S. Ayza, "Design of short high-power TE ${ }_{11^{-}}$ $\mathrm{HE}_{11}$ mode converters in highly overmoded corrugated caveguides", IEEE Trans. Microwave Theory Tech., Vol. 39, pp. 301-309, Feb. 1991.

[3] T. ul Haq, K.J. Webb and, N.C. Gallagher, "Scattering optimization method for the design of compact mode converters for waveguides", IEEE Trans. Microwave Theory Tech., Vol. 43, pp. 669-565, Mar. 1995.

[4] M. Otsuka, M. Shimizu and M. Nishi, "Development of mode converters for $28 \mathrm{GHz}$ electron cyclotron heating system", Int. J. Electronics, Vol. 70, pp. 989-1004, No. 5, 1991.

[5] M.J. Buckley, D.A. Stein and R.J. Vernon, "A single-periodic $\mathrm{TE}_{02}-\mathrm{TE}_{01}$ mode converter in a highly overmoded circular waveguide", IEEE Trans. Microwave Theory Tech., Vol. 39, pp. 1301-1306, Aug. 1991.

[6] M.J. Buckley and R.J. Vernon, "Compact quasi-periodic and aperiodic $\mathrm{TE}_{0 \mathrm{n}}$ mode converters for use with gyrotrons", IEEE Trans. Microwave Theory Tech., Vol. 38, pp. 712-721, June 1990.

[7] H. Kumric, M. Thumm and R. Wilhelm, "Optimization of mode converters for generating the fundamental $\mathrm{TE}_{01}$ mode from $\mathrm{TE}_{06}$ gyrotron output at 140 GHz", Int. J. Electronics, Vol. 64, pp. 77-94, No. 1, 1988.

[8] M. Thumm, H. Kumric and H. Stickel, "TE 03 to $\mathrm{TE}_{01}$ mode converters for use with a $150 \mathrm{GHz}$ gyrotron", Int. J. Infrared and Millimeter Waves, Vol. 8, pp. 227-240, No. 3, 1987.

[9] M. Thumm, "High-power millimetre-wave mode converters in overmoded circular waveguides using periodic wall pertubations", Int. J. Electronics, Vol. 70, pp. 1225-1246, No. 6, 1984.

[10] J. Uher, J. Bornemann and U. Rosenberg, Waveguide Components for Antenna Feed Systems. Theory and CAD, Artech House, Norwood 1993.

[11] S. Amari, R. Vahldieck and J. Bornemann, "Edge-conditioned vector basis functions for the analysis of corrugated antenna feeds", in 1998 IEEE AP-S Int. Symp. Dig., pp. 268-271, Atlanta, USA, June 1998.

[12] J. Bornemann, U. Rosenberg, S. Amari and R. Vahldieck, "Edge-conditioned vector basis functions for the analysis and optimization of rectangular waveguide dual-mode filters", in 1999 IEEE MTT-S Int. Microwave Symp. Dig., pp. 1695-1698, Anaheim, USA, June 1999.

[13] J. Bornemann, S. Amari and R. Vahldieck, "Analysis of waveguide discontinuities by the coupled-integral-equations technique", Recent Research Developments in Microwave Therory and Techniques, in press.

[14] K. Madsen, H. Schaer-Jacobsen and J. Voldby, "Automated minimax design of networks," IEEE Trans. Circuits Systems, Vol. CAS-22, pp. 791-796, Oct. 1975.

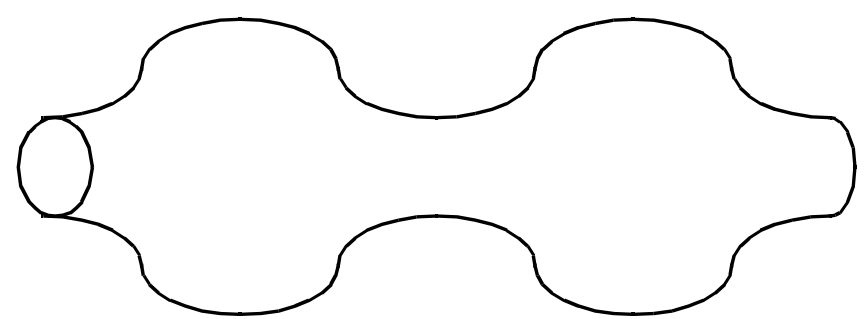

Fig. 1 Example of a periodic continuous-profile circular waveguide $\mathrm{TE}_{0 \mathrm{n}}$-mode converter. 


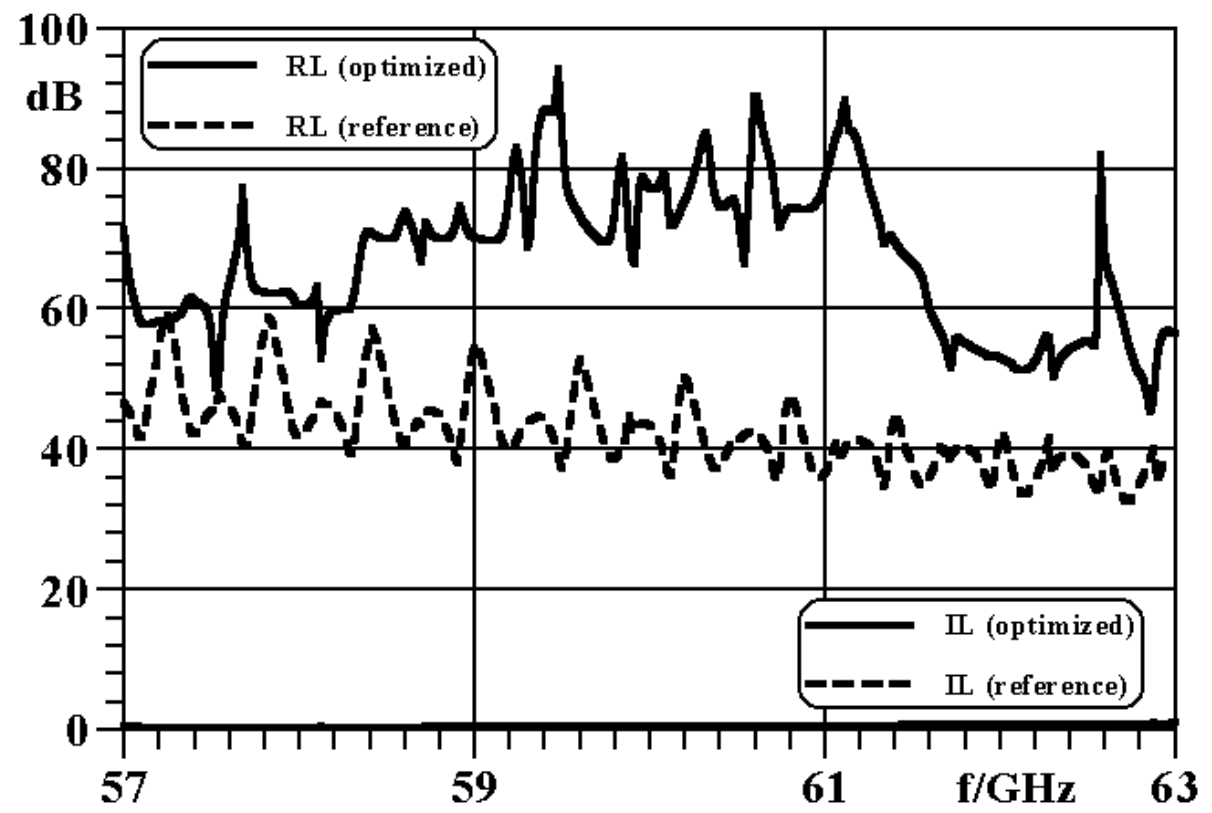

Fig. 2 Performance of reference [5] (dashed lines) and optimized (solid lines) $60 \mathrm{GHz} \mathrm{TE}_{02}$-to- $\mathrm{TE}_{01}$-mode converter. Shown are $\mathrm{TE}_{02}$-to-TE $\mathrm{T}_{02}$-mode return loss and $\mathrm{TE}_{02}$-to- $\mathrm{TE}_{01}$-mode insertion loss.

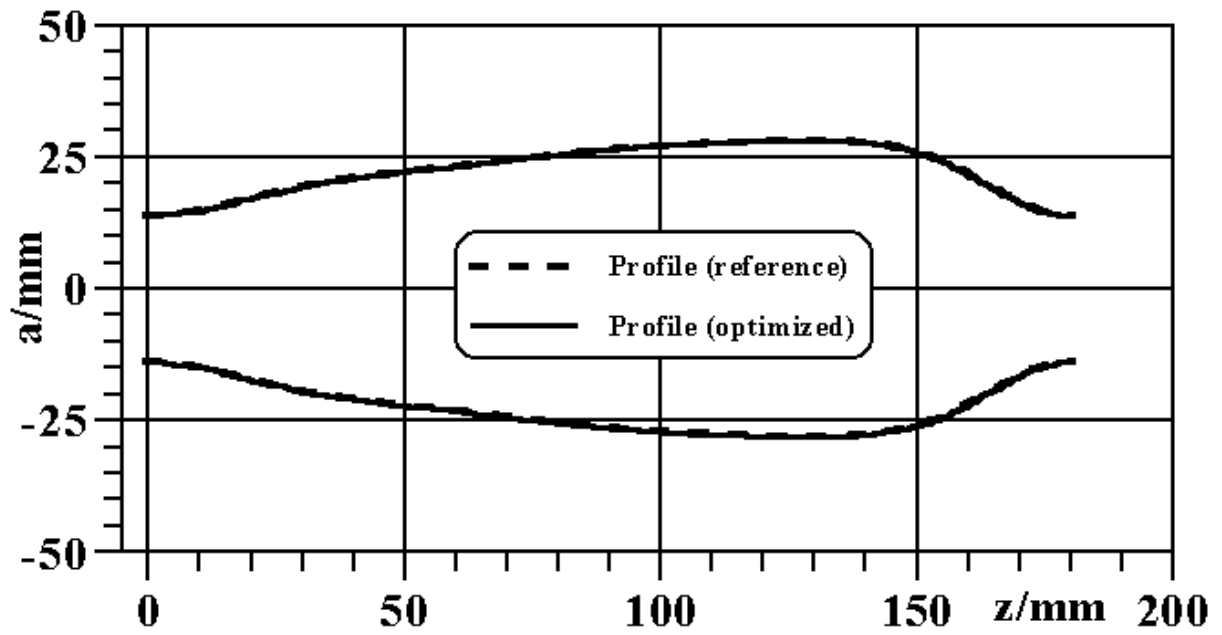

Fig. 3 Continuous profiles of reference [5] (dashed lines) and optimized (solid lines) $60 \mathrm{GHz} \mathrm{TE}_{02}$-to- $\mathrm{TE}_{01}$-mode converter. 